\title{
Association of a polymorphism of $R O R 2$ and ischemic stroke in Japanese individuals with chronic kidney disease
}

\author{
MITSUTOSHI OGURI $^{1}$, TAKANORI NAGAHIRO ${ }^{1}$, HARUO KAMIYA ${ }^{1}$, MIYOSHI OHNO $^{1}$, KIMIHIKO KATO ${ }^{2}$, \\ KIYOSHI YOKOI ${ }^{2}$, TETSURO YOSHIDA ${ }^{3}$, SACHIRO WATANABE $^{4}$, NORIFUMI METOKI ${ }^{5}$, HIDEMI YOSHIDA ${ }^{6}$, \\ KEI SATOH $^{6}$, YUKITOSHI AOYAGI ${ }^{7}$, YOSHINORI NOZAWA ${ }^{8}$ and YOSHIJI YAMADA ${ }^{9}$ \\ ${ }^{1}$ Department of Cardiology, Japanese Red Cross Nagoya First Hospital, Nagoya; ${ }^{2}$ Department of Cardiovascular Medicine, \\ Gifu Prefectural Tajimi Hospital, Tajimi; ${ }^{3}$ Department of Cardiovascular Medicine, Inabe General Hospital, Inabe; \\ ${ }^{4}$ Department of Cardiology, Gifu Prefectural General Medical Center, Gifu; ${ }^{5}$ Department of Internal Medicine, \\ Hirosaki Stroke Center, Hirosaki; ${ }^{6}$ Department of Vascular Biology, Institute of Brain Science, Hirosaki University \\ Graduate School of Medicine, Hirosaki; ${ }^{7}$ Department of Genomics for Longevity and Health, Tokyo Metropolitan Institute \\ of Gerontology, Tokyo; ${ }^{8} \mathrm{Gifu}$ International Institute of Biotechnology and Tokai Gakuin University, Kakamigahara; \\ ${ }^{9}$ Department of Human Functional Genomics, Life Science Research Center, Mie University, Mie, Japan
}

Received October 22, 2009; Accepted December 15, 2009

DOI: 10.3892/etm_00000059

\begin{abstract}
Although chronic kidney disease (CKD) is recognized as an important risk factor for ischemic stroke, genetic factors underlying predisposition to ischemic stroke in individuals with or without CKD remain largely unknown. The aim of the present study was to identify genetic variants that confer susceptibility to ischemic stroke in individuals with or without CKD in order to allow prediction of genetic risk for such individuals separately. The study population comprised 974 individuals with CKD, including 227 subjects with ischemic stroke and 747 controls, and 3,470 individuals without CKD, including 612 subjects with ischemic stroke and 2,858 controls. The 150 polymorphisms examined in the present study were selected by genome-wide association studies of ischemic stroke and myocardial infarction with the use of the GeneChip Human Mapping 500K Array Set (Affymetrix). In individuals with $C K D$, an initial Chi-square test revealed that the $A \rightarrow G$ polymorphism (rs10992119) of the receptor tyrosine kinaselike orphan receptor 2 gene (ROR2) was significantly (false discovery rate for allele frequency, 0.0478) associated with ischemic stroke. Multivariable logistic regression analysis with adjustment for covariates revealed that the $\mathrm{A} \rightarrow \mathrm{G}$ polymorphism of $R O R 2$ was significantly $(\mathrm{P}=0.0100)$ associated with ischemic stroke (recessive model; odds ratio 1.57; 95\% CI 1.12-2.23), with the $G$ allele representing a risk factor for this condition. A stepwise forward selection procedure demonstrated that this
\end{abstract}

Correspondence to: Dr Yoshiji Yamada, Department of Human Functional Genomics, Life Science Research Center, Mie University, 1577 Kurima-machiya, Tsu, Mie 514-8507, Japan.

E-mail: yamada@gene.mie-u.ac.jp

Key words: ischemic stroke, cerebral infarction, chronic kidney disease, genetics, polymorphism polymorphism was a significant $(\mathrm{P}=0.0095)$ and independent determinant of ischemic stroke. In individuals without CKD, no polymorphism was significantly related to ischemic stroke. Genotyping for ROR2 may prove informative for assessment of the genetic risk for ischemic stroke in Japanese individuals with CKD. Determination of the genotype for this polymorphism may prove informative for assessment of the genetic risk for ischemic stroke in such individuals.

\section{Introduction}

Ischemic stroke is a multifactorial and polygenic disease, and is strongly influenced by a genetic component (1-3). Although genome-wide association studies have implicated various candidate genes underlying predisposition to ischemic stroke (4-6), the genes that confer susceptibility to this condition remain to be identified definitively.

It is increasingly recognized that chronic kidney disease (CKD) is an independent risk factor for atherosclerotic diseases including ischemic stroke. Individuals with CKD are at increased risk not only for end stage renal disease but also for a poor cardiovascular outcome and premature death (7-9). Furthermore, many uncertainties exist regarding genetic contribution to ischemic stroke in individuals with CKD.

We performed an association study for 150 polymorphisms of 144 candidate genes and ischemic stroke in 4,444 Japanese individuals with or without CKD. The aim of the present study was to identify genetic variants that confer susceptibility to ischemic stroke in individuals with or without CKD in order to allow prediction of genetic risk for such individuals separately.

\section{Materials and methods}

Study population. The study population comprised 4,444 unrelated Japanese individuals (2,113 men, 2,331 women) 
who either visited outpatient clinics or were admitted to one of the five participating hospitals (Gifu Prefectural General Medical Center, Gifu Prefectural Tajimi Hospital in Gifu Prefecture, Japan; and Hirosaki University Hospital, Reimeikyo Rehabilitation Hospital, and Hirosaki Stroke Center in Aomori Prefecture, Japan) between October 2002 and March 2008, due to various symptoms or for an annual health checkup, or individuals who were recruited to a population-based prospective cohort study of aging and age-related diseases in Nakanojo, Gunma Prefecture, Japan. The study subjects comprised 974 people with CKD (227 subjects with ischemic stroke and 747 controls) and 3,470 people without CKD (612 subjects with ischemic stroke and 2,858 controls). Estimated glomerular filtration rate (eGFR) was calculated with the use of the simplified prediction equation proposed by the Japanese Society of Nephrology and based on that described in the Modification of Diet in Renal Disease study (10): eGFR (ml min-1 $\left.1.73 \mathrm{~m}^{-2}\right)$ $=194 \times$ [age $($ years $)]^{-0.287} \times$ [serum creatinine $\left.(\mathrm{mg} / \mathrm{dl})\right]^{-1.094}$ (x 0.739 if female). The National Kidney Foundation-Kidney Disease Outcome Quality Initiative guidelines recommend a diagnosis of CKD when eGFR is $<60 \mathrm{ml} \mathrm{min}^{-1} 1.73 \mathrm{~m}^{-2}$ (11), on the basis of which 974 subjects in the present study were diagnosed with CKD. The diagnosis of ischemic stroke was based on the occurrence of a new and abrupt focal neurological deficit, with neurological symptoms and signs persisting for $>24 \mathrm{~h}$; it was confirmed by positive findings in computed tomography or magnetic resonance imaging (or both) of the head. The type of stroke was determined according to the Classification of Cerebrovascular Diseases III (12). Individuals with cardiogenic embolic infarction, lacunar infarction alone, transient ischemic attack, moyamoya disease, or cerebral venous sinus thrombosis were excluded from the study, as were those with atrial fibrillation in the absence or presence of valvular heart disease. The 3,605 control subjects were recruited from community-dwelling individuals or the patients who visited outpatient clinics regularly for treatment of various common diseases. They had no history of ischemic or hemorrhagic stroke or other cerebral diseases; of coronary heart disease, aortic aneurysm, or peripheral arterial occlusive disease; or of other atherosclerotic, thrombotic, embolic, or hemorrhagic disorders. The study protocol complied with the Declaration of Helsinki and was approved by the Committees on the Ethics of Human Research of Mie University Graduate School of Medicine, Hirosaki University Graduate School of Medicine, Gifu International Institute of Biotechnology, Tokyo Metropolitan Institute of Gerontology and the participating hospitals. Written informed consent was obtained from each participant.

Selection and genotyping of polymorphisms. Our aim was to identify genetic variants associated with ischemic stroke in the Japanese population with or without CKD in a case-control association study by examining the relations of candidate gene polymorphisms to this condition. Polymorphisms examined in the present study (data not shown) were selected from genome-wide association studies of ischemic stroke and myocardial infarction $\left(\mathrm{P}\right.$-value for allele frequency $<1.0 \times 10^{-7}$ ) with the use of the GeneChip Human Mapping 500K Array
Set (Affymetrix, Santa Clara, CA, USA) (13). We have not examined the relation of these polymorphisms to ischemic stroke in the absence or presence of CKD in our previous studies (14-17).

Venous blood $(7 \mathrm{ml})$ was collected in tubes containing $50 \mathrm{mmol} / \mathrm{l}$ ethylenediaminetetraacetic acid (disodium salt), the peripheral blood leukocytes were isolated, and genomic DNA was extracted from these cells with a DNA extraction kit (Genomix; Talent, Trieste, Italy). Genotypes of the 150 polymorphisms were determined at G\&G Science (Fukushima, Japan) by a method that combines the polymerase chain reaction and sequence-specific oligonucleotide probes with suspension array technology (Luminex, Austin, TX, USA). Primers, probes and other conditions for genotyping of polymorphisms related to ischemic stroke are shown in Table I. Detailed genotyping methodology has been described previously (18).

Statistical analysis. Quantitative data were compared between subjects with ischemic stroke and controls by the unpaired Student's t-test. Categorical data were compared by the Chi-square test. Allele frequencies were estimated by the gene counting method, and the Chi-square test was used to identify departure from Hardy-Weinberg equilibrium. In an initial screen, the genotype distributions (3x2) and allele frequencies $(2 \times 2)$ of each polymorphism were compared between subjects with ischemic stroke and controls by the Chi-square test. Given the multiple comparisons of genotypes, the false discovery rate (FDR) was calculated by the method of Benjamini and Hochberg (19) from the distribution of P-values for allele frequencies of the 150 polymorphisms. Polymorphisms with an FDR of $<0.05$ were further examined by multivariable logistic regression analysis with adjustment for covariates that differed significantly between subjects with ischemic stroke and controls. Multivariable logistic regression analysis was thus performed with ischemic stroke as a dependent variable and independent variables including age, gender (0, woman; 1, man), serum concentration of creatinine, and the prevalence of hypertension, diabetes mellitus and hypercholesterolemia ( 0 , no history of these conditions; 1 , positive history), the genotype of each polymorphism, and the P-value, odds ratio and 95\% CI were calculated. Each genotype was assessed according to dominant, recessive and additive genetic models. Additive models included the additive 1 model (heterozygotes vs. wild-type homozygotes) and the additive 2 model (variant homozygotes vs. wild-type homozygotes), which were analyzed simultaneously with a single statistical model. We also performed a stepwise forward selection procedure to examine the effects of genotypes as well as other covariates on ischemic stroke. In the stepwise forward selection procedure, each genotype was examined according to a dominant or recessive model on the basis of statistical significance in the multivariable logistic regression analysis. With the exception of the initial screen by the Chi-square test (FDR $<0.05$ ), a P-value of $<0.05$ was considered statistically significant. Statistical significance was examined by two-sided tests performed with JMP version 5.1 software and JMP Genomics version 3.2 software (SAS Institute, Cary, NC, USA). 


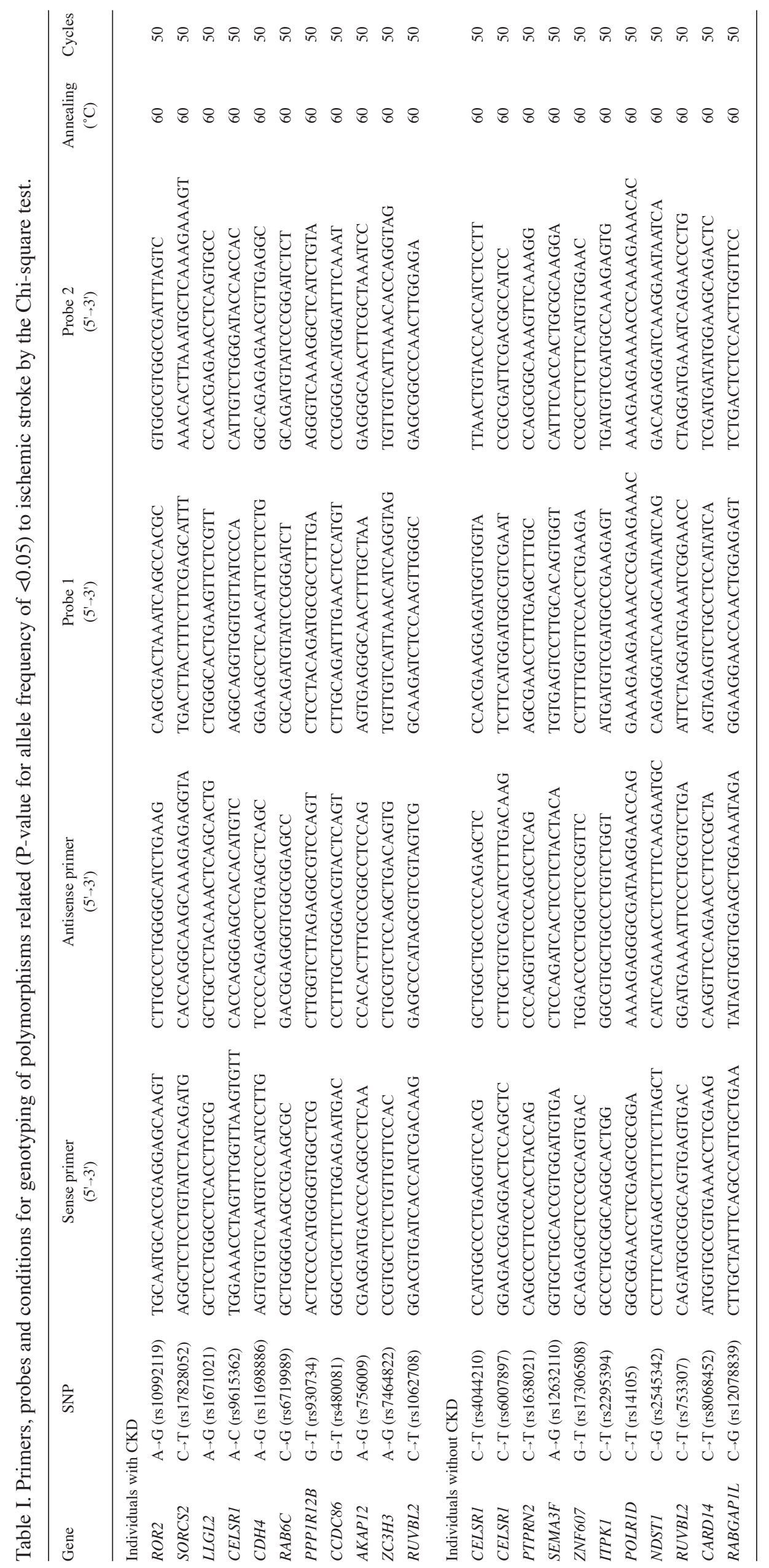


Table II. Characteristics of the study subjects.

\begin{tabular}{|c|c|c|c|c|c|c|}
\hline \multirow[b]{2}{*}{ Characteristic } & \multicolumn{3}{|c|}{ Subjects with CKD } & \multicolumn{3}{|c|}{ Subjects without CKD } \\
\hline & Ischemic stroke & Controls & P-value & Ischemic stroke & Controls & P-value \\
\hline No. of subjects & 227 & 747 & & 612 & 2858 & \\
\hline Age (years) & $72.5 \pm 7.52$ & $70.5 \pm 9.37$ & 0.0010 & $68.5 \pm 10.4$ & $64.6 \pm 11.3$ & $<0.0001$ \\
\hline Gender (males/females, \%) & $68.7 / 31.3$ & $48.5 / 51.5$ & $<0.0001$ & $55.9 / 44.1$ & $43.8 / 56.2$ & $<0.0001$ \\
\hline Body mass index $\left(\mathrm{kg} / \mathrm{m}^{2}\right)$ & $23.3 \pm 3.3$ & $23.6 \pm 3.5$ & 0.3000 & $23.7 \pm 3.4$ & $23.3 \pm 3.3$ & 0.0899 \\
\hline Current or former smoker $(\%)$ & 17.2 & 21.3 & 0.1784 & 15.9 & 18.6 & 0.1114 \\
\hline Hypertension (\%) & 85.0 & 49.4 & $<0.0001$ & 65.0 & 37.1 & $<0.0001$ \\
\hline Systolic blood pressure (mmHg) & $154 \pm 28$ & $138 \pm 23$ & $<0.0001$ & $150 \pm 27$ & $137 \pm 20$ & $<0.0001$ \\
\hline Diastolic blood pressure ( $\mathrm{mmHg}$ ) & $83 \pm 16$ & $79 \pm 14$ & 0.0008 & $85 \pm 16$ & $73 \pm 12$ & $<0.0001$ \\
\hline Hypercholesterolemia (\%) & 37.0 & 29.7 & 0.0384 & 25.7 & 23.5 & 0.2518 \\
\hline Serum total cholesterol $(\mathrm{mmol} / \mathrm{l})$ & $5.36 \pm 1.12$ & $5.16 \pm 0.98$ & 0.0251 & $5.09 \pm 1.03$ & $5.12 \pm 0.88$ & 0.6227 \\
\hline Serum triglyceride $(\mathrm{mmol} / \mathrm{l})$ & $1.74 \pm 1.14$ & $1.62 \pm 1.00$ & 0.1922 & $1.53 \pm 0.82$ & $1.49 \pm 1.02$ & 0.3513 \\
\hline Serum HDL-cholesterol (mmol/l) & $1.30 \pm 0.39$ & $1.45 \pm 0.40$ & $<0.0001$ & $1.25 \pm 0.37$ & $1.50 \pm 0.39$ & $<0.0001$ \\
\hline Serum LDL-cholesterol (mmol/l) & $3.29 \pm 0.93$ & $2.97 \pm 0.87$ & $<0.0001$ & $3.16 \pm 0.91$ & $2.94 \pm 0.80$ & 0.0002 \\
\hline Diabetes mellitus (\%) & 48.5 & 20.1 & $<0.0001$ & 34.0 & 12.3 & $<0.0001$ \\
\hline Fasting plasma glucose $(\mathrm{mmol} / \mathrm{l})$ & $7.21 \pm 2.82$ & $6.57 \pm 2.91$ & 0.0058 & $7.26 \pm 2.90$ & $6.39 \pm 2.59$ & $<0.0001$ \\
\hline Glycosylated hemoglobin (\%) & $6.08 \pm 1.40$ & $5.55 \pm 1.23$ & 0.0006 & $6.03 \pm 1.49$ & $5.55 \pm 1.30$ & $<0.0001$ \\
\hline Serum creatinine $(\mu \mathrm{mol} / \mathrm{l})$ & $96.9 \pm 89.0$ & $81.5 \pm 60.4$ & 0.0153 & $54.3 \pm 10.8$ & $52.0 \pm 10.3$ & 0.0003 \\
\hline eGFR (ml min'-1 $\left.1.73 \mathrm{~m}^{-2}\right)$ & $47.5 \pm 10.8$ & $50.8 \pm 8.9$ & $<0.0001$ & $77.8 \pm 15.1$ & $78.5 \pm 15.9$ & 0.4580 \\
\hline
\end{tabular}

Quantitative data are the mean \pm SD. Hypertension: systolic blood pressure of $\geq 140 \mathrm{mmHg}$, diastolic blood pressure of $\geq 90 \mathrm{mmHg}$, or taking antihypertensive medication. Hypercholesterolemia: serum total cholesterol of $\geq 5.72 \mathrm{mmol} / 1$ or taking lipid-lowering medication. Diabetes mellitus: fasting blood glucose of $\geq 6.93 \mathrm{mmol} / 1$, glycosylated hemoglobin (hemoglobin $\mathrm{A}_{1 \mathrm{c}}$ ) content of $\geq 6.5 \%$, or taking antidiabetes medication. HDL, high-density lipoprotein; LDL, low-density lipoprotein; eGFR, estimated glomerular filtration rate.

\section{Results}

The characteristics of the study subjects are documented in Table II. In individuals with CKD, age, the frequency of males, prevalence of hypertension, hypercholesterolemia and diabetes mellitus, as well as systolic and diastolic blood pressure, serum concentrations of total cholesterol, low-density lipoprotein (LDL)-cholesterol and creatinine, fasting plasma glucose level and blood glycosylated hemoglobin content were greater, whereas serum concentration of high-density lipoprotein (HDL)-cholesterol and eGFR were lower in the subjects with ischemic stroke than in the controls. In individuals without CKD, age, the frequency of males, the prevalence of hypertension and diabetes mellitus, as well as systolic and diastolic blood pressure, serum concentrations of LDL-cholesterol and creatinine, fasting plasma glucose level and blood glycosylated hemoglobin content were greater, whereas the serum concentration of HDL-cholesterol was lower in subjects with ischemic stroke than in the controls.

Evaluation of allele frequencies by the Chi-square test revealed that eleven polymorphisms were related (P-value for allele frequency of $<0.05$ ) to the prevalence of ischemic stroke in individuals with CKD. Among these polymorphisms, the $\mathrm{A} \rightarrow \mathrm{G}$ polymorphism (rs10992119) of the receptor tyrosine kinase-like orphan receptor 2 gene (ROR2) was significantly (FDR for allele frequency of $<0.05$ ) associated with the prevalence of ischemic stroke (Table III). The genotype distributions for 11 polymorphisms related to ischemic stroke in individuals with CKD are also documented in Table III. In individuals without CKD, another set of 11 polymorphisms was related (P-value for allele frequency of $<0.05$ ) to the prevalence of ischemic stroke, but no polymorphism was significantly (FDR for allele frequency of $<0.05$ ) related to ischemic stroke (Table IV). The genotype distributions for 11 polymorphisms related to ischemic stroke in individuals without CKD are also shown in Table IV. In control subjects, the genotype distributions of these polymorphisms with the exception of those of POLRID and RUVBL2 were in HardyWeinberg equilibrium (data not shown).

Multivariable logistic regression analysis with adjustment for age, gender, serum concentration of creatinine, and the prevalence of hypertension, diabetes mellitus and hypercholesterolemia revealed that the $A \rightarrow G$ polymorphism of $R O R 2$ (recessive and additive 2 models) was significantly $(\mathrm{P}<0.05)$ associated with ischemic stroke in individuals with CKD, with the $G$ allele representing a risk factor for this condition (Table V). A stepwise forward selection procedure was performed to examine the effects of the ROR2 genotype as well as of age, gender, serum concentration of creatinine, and the prevalence of hypertension, diabetes mellitus and hypercholesterolemia on ischemic stroke (Table VI). Hypertension, diabetes mellitus, gender, age, ROR2 genotype (recessive model) and hypercholesterolemia, in descending 
Table III. Polymorphisms related (P-value for allele frequency of $<0.05$ ) to ischemic stroke in subjects with CKD as determined by the Chi-square test.

\begin{tabular}{|c|c|c|c|c|c|c|c|}
\hline $\begin{array}{l}\text { Gene } \\
\text { Symbol }\end{array}$ & Polymorphism & dbSNP & $\begin{array}{l}\text { Ischemic } \\
\text { stroke }(\%)\end{array}$ & $\begin{array}{c}\text { Controls } \\
(\%)\end{array}$ & $\begin{array}{l}\text { P-value } \\
\text { (genotype) }\end{array}$ & $\begin{array}{l}\text { P-value } \\
\text { (allele) }\end{array}$ & $\begin{array}{c}\text { FDR } \\
\text { (allele) }\end{array}$ \\
\hline$R O R 2$ & $\begin{array}{c}\mathrm{A} \rightarrow \mathrm{G} \\
A A \\
A G \\
G G\end{array}$ & rs 10992119 & $\begin{array}{rr}6 & (2.7) \\
70(31.1) \\
149(66.2)\end{array}$ & $\begin{array}{r}52(7.0) \\
284(38.3) \\
406(54.7)\end{array}$ & 0.0027 & 0.0006 & 0.0478 \\
\hline SORCS2 & $\begin{array}{c}\mathrm{C} \rightarrow \mathrm{T} \\
C C \\
C T \\
T T\end{array}$ & rs 17828052 & $\begin{array}{r}179(79.2) \\
40(17.7) \\
7 \quad(3.1)\end{array}$ & $\begin{array}{r}625(84.9) \\
108(14.7) \\
3 \quad(0.4)\end{array}$ & 0.0010 & 0.0056 & 0.2255 \\
\hline$L L G L 2$ & $\begin{array}{c}\mathrm{A} \rightarrow \mathrm{G} \\
A A \\
A G \\
G G\end{array}$ & rs1671021 & $\begin{array}{r}181(79.7) \\
42(18.5) \\
4 \quad(1.8)\end{array}$ & $\begin{array}{r}529(71.0) \\
197(26.4) \\
19 \quad(2.6)\end{array}$ & 0.0345 & 0.0121 & 0.2694 \\
\hline CELSRI & $\begin{array}{l}\mathrm{A} \rightarrow \mathrm{C} \\
A A \\
A C \\
C C\end{array}$ & rs9615362 & $\begin{array}{c}0 \\
12(5.3) \\
213(94.7)\end{array}$ & $\begin{array}{rr}0 & \\
16 & (2.2) \\
726 & (97.8)\end{array}$ & 0.0128 & 0.0135 & 0.2694 \\
\hline $\mathrm{CDH} 4$ & $\begin{array}{l}\mathrm{A} \rightarrow \mathrm{G} \\
A A \\
A G \\
G G\end{array}$ & rs11698886 & $\begin{array}{r}24(10.7) \\
108(48.0) \\
93(41.3)\end{array}$ & $\begin{array}{l}123(16.6) \\
355(47.8) \\
264(35.6)\end{array}$ & 0.0634 & 0.0264 & 0.3277 \\
\hline$R A B 6 C$ & $\begin{array}{l}\mathrm{C} \rightarrow \mathrm{G} \\
C C \\
C G \\
G G\end{array}$ & rs6719989 & $\begin{array}{r}166(73.8) \\
54(24.0) \\
5 \quad(2.2)\end{array}$ & $\begin{array}{r}594(80.1) \\
141(19.0) \\
7 \quad(0.9)\end{array}$ & 0.0714 & 0.0268 & 0.3277 \\
\hline PPPIR12B & $\begin{array}{c}\mathrm{G} \rightarrow \mathrm{T} \\
G G \\
G T \\
T T\end{array}$ & rs930734 & $\begin{array}{r}130(57.8) \\
80(35.5) \\
15 \quad(6.7)\end{array}$ & $\begin{array}{r}362(48.8) \\
319(43.0) \\
61 \quad(8.2)\end{array}$ & 0.0612 & 0.0300 & 0.3277 \\
\hline CCDC86 & $\begin{array}{l}\mathrm{G} \rightarrow \mathrm{T} \\
G G \\
G T \\
T T\end{array}$ & rs480081 & $\begin{array}{r}28(12.5) \\
95(42.2) \\
102(45.3)\end{array}$ & $\begin{array}{rr}60 & (8.1) \\
302 & (40.7) \\
380 & (51.2)\end{array}$ & 0.0864 & 0.0372 & 0.3277 \\
\hline AKAP12 & $\begin{array}{c}\mathrm{A} \rightarrow \mathrm{G} \\
A A \\
A G \\
G G\end{array}$ & rs756009 & $\begin{array}{c}0 \\
0 \\
225(100)\end{array}$ & $\begin{array}{cc}0 & \\
14 & (1.9) \\
728 & (98.1)\end{array}$ & 0.0379 & 0.0386 & 0.3277 \\
\hline ZC $3 H 3$ & $\begin{array}{l}\mathrm{A} \rightarrow \mathrm{G} \\
A A \\
A G \\
G G\end{array}$ & rs7464822 & $\begin{array}{r}2(0.9) \\
29(12.8) \\
195(86.3)\end{array}$ & $\begin{array}{rr}4 & (0.5) \\
63 & (8.6) \\
669 & (90.9)\end{array}$ & 0.1331 & 0.0416 & 0.3277 \\
\hline$R U V B L 2$ & $\begin{array}{l}\mathrm{C} \rightarrow \mathrm{T} \\
C C \\
C T \\
T T\end{array}$ & rs 1062708 & $\begin{array}{r}73(32.3) \\
116(51.3) \\
37(16.4)\end{array}$ & $\begin{array}{l}210(28.6) \\
355(48.2) \\
171(23.2)\end{array}$ & 0.0847 & 0.0474 & 0.3277 \\
\hline
\end{tabular}

order of statistical significance, were significant $(\mathrm{P}<0.05)$ and independent determinants of ischemic stroke in individuals with CKD.
Finally, we examined the relation of the $A \rightarrow G$ polymorphism of ROR2 to intermediate phenotypes, including systolic and diastolic blood pressure, fasting plasma 
Table IV. Polymorphisms related (P-value for allele frequency of $<0.05$ ) to ischemic stroke in subjects without CKD as determined by the Chi-square test.

\begin{tabular}{|c|c|c|c|c|c|c|c|}
\hline $\begin{array}{l}\text { Gene } \\
\text { Symbol }\end{array}$ & Polymorphism & dbSNP & $\begin{array}{c}\text { Ischemic } \\
\text { stroke }(\%)\end{array}$ & $\begin{array}{c}\text { Controls } \\
(\%)\end{array}$ & $\begin{array}{l}\text { P-value } \\
\text { (genotype) }\end{array}$ & $\begin{array}{l}\text { P-value } \\
\text { (allele) }\end{array}$ & $\begin{array}{c}\text { FDR } \\
\text { (allele) }\end{array}$ \\
\hline \multirow[t]{4}{*}{ CELSRI } & $\mathrm{C} \rightarrow \mathrm{T}$ & rs4044210 & & & 0.0113 & 0.0121 & 0.5894 \\
\hline & $C C$ & & 0 & 0 & & & \\
\hline & $C T$ & & 34 (5.6) & 96 (3.4) & & & \\
\hline & $T T$ & & 577 (94.4) & 2723 (96.6) & & & \\
\hline \multirow[t]{4}{*}{ CELSRI } & $\mathrm{C} \rightarrow \mathrm{T}$ & rs6007897 & & & 0.0115 & 0.0123 & 0.5894 \\
\hline & $C C$ & & 0 & 0 & & & \\
\hline & $C T$ & & $32(5.2)$ & 89 (3.2) & & & \\
\hline & $T T$ & & $579(94.8)$ & $2730(96.8)$ & & & \\
\hline \multirow[t]{4}{*}{ PTPRN2 } & $\mathrm{C} \rightarrow \mathrm{T}$ & rs1638021 & & & 0.0463 & 0.0129 & 0.5894 \\
\hline & $C C$ & & $289(47.3)$ & $1479(52.5)$ & & & \\
\hline & $C T$ & & $262(42.9)$ & 1117 (39.6) & & & \\
\hline & $T T$ & & $60 \quad(9.8)$ & $223(7.9)$ & & & \\
\hline \multirow[t]{4}{*}{ SEMA3F } & $\mathrm{A} \rightarrow \mathrm{G}$ & rs12632110 & & & 0.0614 & 0.0192 & 0.5894 \\
\hline & $A A$ & & $144(23.5)$ & $571(20.3)$ & & & \\
\hline & $A G$ & & $313(51.2)$ & $1417(50.3)$ & & & \\
\hline & $G G$ & & $155(25.3)$ & 829 (29.4) & & & \\
\hline \multirow[t]{4}{*}{ ZNF607 } & $\mathrm{G} \rightarrow \mathrm{T}$ & rs17306508 & & & 0.0832 & 0.0266 & 0.5894 \\
\hline & $G G$ & & $517(84.9)$ & 2498 (88.2) & & & \\
\hline & $G T$ & & 88 (14.5) & $321(11.3)$ & & & \\
\hline & $T T$ & & $4(0.6)$ & $14(0.5)$ & & & \\
\hline \multirow[t]{4}{*}{ ITPKI } & $\mathrm{C} \rightarrow \mathrm{T}$ & rs2295394 & & & 0.0885 & 0.0291 & 0.5894 \\
\hline & $C C$ & & 364 (59.6) & $1547(54.9)$ & & & \\
\hline & $C T$ & & $215(35.2)$ & 1088 (38.6) & & & \\
\hline & $T T$ & & $32 \quad(5.2)$ & 184 & & & \\
\hline \multirow[t]{4}{*}{ POLRID } & $\mathrm{C} \rightarrow \mathrm{T}$ & rs 14105 & & & 0.0908 & 0.0323 & 0.5894 \\
\hline & $C C$ & & $248(40.7)$ & $1059(37.4)$ & & & \\
\hline & $C T$ & & $280(46.0)$ & $1305(46.1)$ & & & \\
\hline & $T T$ & & $81(13.3)$ & 469 (16.5) & & & \\
\hline \multirow[t]{4}{*}{ NDST1 } & $\mathrm{C} \rightarrow \mathrm{G}$ & rs2545342 & & & 0.1085 & 0.0362 & 0.5894 \\
\hline & $C C$ & & $5(0.8)$ & 37 (1.3) & & & \\
\hline & $C G$ & & $110(18.0)$ & 597 (21.2) & & & \\
\hline & $G G$ & & 497 (81.2) & 2182 (77.5) & & & \\
\hline \multirow[t]{4}{*}{$R U V B L 2$} & $\mathrm{C} \rightarrow \mathrm{T}$ & rs753307 & & & 0.0111 & 0.0377 & 0.5894 \\
\hline & $C C$ & & 304 (49.9) & $1358(47.9)$ & & & \\
\hline & $C T$ & & $262(43.0)$ & 1159 (40.9) & & & \\
\hline & $T T$ & & $43 \quad(7.1)$ & $316(11.2)$ & & & \\
\hline \multirow[t]{4}{*}{ CARDI4 } & $\mathrm{C} \rightarrow \mathrm{T}$ & rs8068452 & & & 0.0374 & 0.0447 & 0.5894 \\
\hline & $C C$ & & $36(5.9)$ & $257 \quad(9.1)$ & & & \\
\hline & $C T$ & & $248(40.7)$ & $1137(40.1)$ & & & \\
\hline & $T T$ & & $325(53.4)$ & $1439(50.8)$ & & & \\
\hline \multirow[t]{4}{*}{$R A B G A P I L$} & $\mathrm{C} \rightarrow \mathrm{G}$ & rs 12078839 & & & 0.0144 & 0.0451 & 0.5894 \\
\hline & $C C$ & & $480(78.8)$ & 2308 (81.5) & & & \\
\hline & $C G$ & & 118 (19.4) & $506(17.8)$ & & & \\
\hline & $G G$ & & 11 & $19(0.7)$ & & & \\
\hline
\end{tabular}

glucose level, blood glycosylated hemoglobin content, serum concentrations of total cholesterol, triglycerides and HDL-cholesterol, and Body Mass Index (BMI). The
Chi-square test did not detect any relation between ROR2 genotype and either of the intermediate phenotypes (data not shown). 
Table V. Multivariable logistic regression analysis of a polymorphism associated with ischemic stroke by the Chi-square test in individuals with CKD.

\begin{tabular}{|c|c|c|c|c|c|c|c|c|c|}
\hline \multirow[t]{2}{*}{ Gene } & \multirow[t]{2}{*}{ Polymorphism } & \multicolumn{2}{|c|}{ Dominant } & \multicolumn{2}{|c|}{ Recessive } & \multicolumn{2}{|c|}{ Additive 1} & \multicolumn{2}{|c|}{ Additive 2} \\
\hline & & P-value & OR $(95 \% \mathrm{CI})$ & P-value & OR $(95 \%$ CI $)$ & P-value & OR $(95 \% \mathrm{CI})$ & P-value & OR $(95 \% \mathrm{CI})$ \\
\hline ROR2 & $\mathrm{A} \rightarrow \mathrm{G}(\mathrm{rs} 10992119)$ & 0.0546 & & 0.0100 & $1.57(1.12-2.23)$ & 0.1791 & & 0.0280 & $2.76(1.20-7.53)$ \\
\hline
\end{tabular}

OR, odds ratio; CI, confidence interval. Multivariable logistic regression analysis was performed with adjustment for age, gender, serum concentration of creatinine and the prevalence of hypertension, diabetes mellitus and hypercholesterolemia.

Table VI. Effects of genotypes and other characteristics on ischemic stroke among individuals with CKD as determined by a stepwise forward selection procedure $(\mathrm{P}<0.05)$.

\begin{tabular}{lrc}
\hline Variable & P-value & $\mathrm{R}^{2}$ \\
\hline Hypertension & $<0.0001$ & 0.0952 \\
Diabetes mellitus & $<0.0001$ & 0.0405 \\
Gender & $<0.0001$ & 0.0224 \\
Age & 0.0003 & 0.0123 \\
ROR2 $(G G$ vs. $A A+A G)$ & 0.0095 & 0.0064 \\
Hypercholesterolemia & 0.0276 & 0.0046 \\
\hline
\end{tabular}

$\mathrm{R}^{2}$, contribution rate.

\section{Discussion}

The main cause of ischemic stroke is atherothrombosis, with the principal and treatable risk factors including hypertension, diabetes mellitus, dyslipidemia and smoking (20). In addition to these conventional risk factors, genetic variants are important in the etiology of ischemic stroke (21). Prediction of the risk for ischemic stroke on the basis of genetic information would be useful for deciding how aggressively to target the clinical risk factors that are currently amenable to treatment. In this study we examined the possible relations of 150 polymorphisms to the prevalence of ischemic stroke in 4,444 Japanese individuals and showed that the $A \rightarrow G$ polymorphism (rs10992119) in intron 1 of ROR2 was significantly associated with ischemic stroke in individuals with CKD.

ROR2 encodes a receptor tyrosine kinase and type 1 transmembrane protein that exists on the cell surface $(22,23)$. Receptor tyrosine kinases are glycoproteins that play important roles in regulating intracellular signaling pathways that control cell proliferation, differentiation, migration, metabolism and apoptosis (24,25). Human ROR2 is expressed in many tissues during development and plays an important role in developmental morphogenesis, including skeletal morphogenesis and bone and cartilage formation (26). Mutations in ROR2 have been reported to cause either of two genetic skeletal disorders: loss-offunction mutations cause Robinow syndrome whereas gain-of-function mutations cause Brachydactyly type B
(27,28). Recently, ROR2 was demonstrated to function as an oncogene and was found to be expressed in gastric cancer with signet ring cell features (29). An increase in ROR2 mRNA expression was observed in the majority of renal cell carcinomas, and protein expression was confirmed at the tumor cell level (30). However, the association between $R O R 2$ and atherosclerotic disease has not been reported. In the present study, we showed that the $A \rightarrow G$ polymorphism of ROR2 (rs10992119) was significantly associated with the prevalence of ischemic stroke in individuals with CKD, with the $G$ allele representing a risk factor for this condition. Given that the ROR genotype did not relate to intermediate phenotypes and that rs10992119 is located in intron 1, the underlying mechanism remains unclear.

There were several limitations in our study. i) We used eGFR instead of a directly measured GFR to define CKD. We did not have information regarding the underlying renal disease for each subject; ii) it is possible that the polymorphism associated with ischemic stroke in the present study is in linkage disequilibrium with other polymorphisms in the same gene or in other nearby genes that are actually responsible for the development of this condition; iii) given that the association of the ROR 2 polymorphism with ischemic stroke in the present study was not replicated in independent subject panels, our study was considered to be hypothesis generating; iv) given that the study population comprised only Japanese individuals, validation of our findings is required in other ethnic groups; and v) the functional relevance of the identified polymorphism of ROR2 with the pathogenesis of ischemic stroke remains to be determined.

In conclusion, our present results suggest that ROR 2 may be a susceptibility locus for ischemic stroke in Japanese individuals with CKD, although the functional relevance to this condition was not determined. Determination of the genotype for this polymorphism may prove informative for the assessment of the genetic risk for ischemic stroke in such individuals. Validation of our findings will require their replication with independent subject panels of various ethnic groups.

\section{Acknowledgements}

This work was supported in part by the Grants-in-Aid for Scientific Research from the Ministry of Education, Culture, Sports, Science and Technology of Japan (nos. 18209023, 18018021 and 19659149 to Y.Y.). 


\section{References}

1. Bak S, Gaist D, Sindrup SH, Skytthe A and Christensen K: Genetic liability in stroke: a long-term follow-up study of Danish twins. Stroke 33: 769-774, 2002.

2. Tournier-Lasserve E: New players in the genetics of stroke. $\mathrm{N}$ Engl J Med 347: 1711-1712, 2002.

3. Touzé E and Rothwell PM: Heritability of ischaemic stroke in women compared with men: a genetic epidemiological study. Lancet Neurol 6: 125-133, 2007.

4. Matarín M, Brown WM, Scholz S, et al: A genome-wide genotyping study in patients with ischaemic stroke: initial analysis and data release. Lancet Neurol 6: 414-420, 2007.

5. Kubo M, Hata J, Ninomiya T, et al: A nonsynonymous SNP in PRKCH (protein kinase C eta) increases the risk of cerebral infarction. Nat Genet 39: 212-217, 2007.

6. Ikram MA, Seshadri S, Bis JC, et al: Genomewide association studies of stroke. N Engl J Med 360: 1718-1728, 2009.

7. Irie $\mathrm{F}$, Iso $\mathrm{H}$, Sairenchi $\mathrm{T}$, et al: The relationships of proteinuria, serum creatinine, glomerular filtration rate with cardiovascular disease mortality in Japanese general population. Kidney Int 69: 1264-1271, 2006.

8. Yahalom G, Schwartz R, Schwammenthal Y, et al: Chronic kidney disease and clinical outcome in patients with acute stroke. Stroke 40: 1296-1303, 2009.

9. Muntner P, He J, Hamm L, Loria C and Whelton PK: Renal insufficiency and subsequent death resulting from cardiovascular disease in the United States. J Am Soc Nephrol 13: 745-753, 2002.

10. Matsuo S, Imai E, Horio M, et al: Revised equations for estimated GFR from serum creatinine in Japan. Am J Kidney Dis 53: 982-992, 2009.

11. Levey AS, Eckardt KU, Tsukamoto Y, et al: Definition and classification of chronic kidney disease: a position statement from Kidney Disease: Improving Global Outcomes (KDIGO). Kidney Int 67: 2089-2100, 2005.

12. A committee established by the Director of the National Institute of Neurological Disorders and Stroke, National Institutes of Health: Special Report from the National Institute of Neurological Disorders and Stroke. Classification of Cerebrovascular Diseases III. Stroke 21: 637-676, 1990.

13. Yamada Y, Fuku N, Tanaka M, et al: Identification of CELSRI as a susceptibility gene for ischemic stroke in Japanese individuals by a genome-wide association study. Atherosclerosis 207: $144-149,2009$

14. Oguri M, Kato K, Yokoi K, et al: Association of a polymorphism of $B C H E$ with ischemic stroke in Japanese individuals with chronic kidney disease. Mol Med Rep 2: 779-785, 2009.

15. Yamada $\mathrm{Y}$, Kato $\mathrm{K}$, Oguri M, et al: Association of genetic variants with atherothrombotic cerebral infarction among Japanese individuals with metabolic syndrome. Int J Mol Med 21: 801-808, 2008 .
16. Yamada Y, Metoki N, Yoshida H, et al: Genetic factors for ischemic and hemorrhagic stroke in Japanese individuals. Stroke 39: 2211-2218, 2008.

17. Yamada Y, Metoki N, Yoshida H, et al: Genetic risk for ischemic and hemorrhagic stroke. Arterioscler Thromb Vasc Biol 26: 1920-1925, 2006

18. Itoh Y, Mizuki N, Shimada T, et al: High-throughput DNA typing of HLA-A, -B, -C and -DRB1 loci by a PCR-SSOP-Luminex method in the Japanese population. Immunogenetics 57: 717-729, 2005.

19. Benjamini $Y$ and Hochberg Y: Controlling the false discovery rate: a practical and powerful approach to multiple testing. J Royal Stat Soc Ser B 57: 289-300, 1995.

20. Goldstein LB, Adams R, Becker K, et al: Primary prevention of ischemic stroke: a statement for healthcare professionals from the Stroke Council of the American Heart Association. Stroke 32: 280-299, 2001.

21. Humphries SE and Morgan L: Genetic risk factors for stroke and carotid atherosclerosis: insights into pathophysiology from candidate gene approaches. Lancet Neurol 3: 227-235, 2004.

22. Masiakowski P and Carroll RD: A novel family of cell surface receptors with tyrosine kinase-like domain. J Biol Chem 267: 26181-26190, 1992.

23. Forrester WC: The Ror receptor tyrosine kinase family. Cell Mol Life Sci 59: 83-96, 2002.

24. Stommel JM, Kimmelman AC, Ying $\mathrm{H}$, et al: Coactivation of receptor tyrosine kinases affects the response of tumor cells to targeted therapies. Science 318: 287-290, 2007.

25. Schlessinger J: Cell signaling by receptor tyrosine kinases. Cell 103: 211-225, 2000.

26. Yoda A, Oishi I and Minami Y: Expression and function of the Ror-family receptor tyrosine kinases during development: lessons from genetic analyses of nematodes, mice and humans. J Recept Signal Transduct Res 23: 1-15, 2003.

27. Afzal AR, Rajab A, Fenske CD, et al: Recessive Robinow syndrome, allelic to dominant brachydactyly type $\mathrm{B}$, is caused by mutation of ROR2. Nat Genet 25: 419-422, 2000.

28. Oldridge M, Fortuna AM, Maringa M, et al: Dominant mutations in ROR2, encoding an orphan receptor tyrosine kinase, cause brachydactyly type B. Nat Genet 24: 275-278, 2000.

29. Katoh $\mathrm{M}$ and Katoh M: Comparative genomics on ROR1 and ROR2 orthologs. Oncol Rep 14: 1381-1384, 2005.

30. Wright TM, Brannon AR, Gordan JD, et al: Ror2, a developmentally regulated kinase, promotes tumor growth potential in renal cell carcinoma. Oncogene 28: 2513-2523, 2009. 